\title{
LA ICONOGRAFÍA DEL BUEN PASTOR NIÑO Y SU VINCULACIÓN CON LA PINTURA BARROCA SEVILLANA
}

\author{
THE ICONOGRAPHY OF THE GOOD SHEPHERD \\ CHILD AND ITS LINKS WITH THE SEVILLIAN \\ BAROQUE PAINTING
}

\author{
Nerea V. PÉrez López \\ nereavperez@gmail.com
}

\begin{abstract}
El Buen Pastor es una de las primeras iconografías cristianas y tiene sus orígenes remotos en las representaciones paganas de Hermes Crióforo y de Orfeo, sin embargo, tras el periodo paleocristiano, su representación se frenó hasta el Renacimiento. En Sevilla, Murillo efectúa una modificación al infantilizar la figura de Cristo. Este nuevo modelo alcanzó un gran éxito y fue continuado por otros pintores sevillanos, como Domingo Martínez y Juan Simón Gutiérrez, que siguieron las líneas del maestro. Valdés Leal fue el único que propuso un modelo diferente.

Palabras clave: Buen Pastor; iconografía barroca; Murillo; Valdés Leal; pintura sevillana.
\end{abstract}

The Good Shepherd counts itself among the first Christian iconographies ever created, its ancient origins are deeply rooted in earlier pagan renditions of mythological characters such as Hermes Criophorus and Orpheus. However, once the Paleo-Christian period was over, this representation of Christ faded away into obscurity until the Renaissance, where it regained popularity. In Seville, Murillo incorporates a significant modification to it, as he infantilizes the figure of Christ. This new model achieves an outstanding success as proven by other talented Sevillian painters such as Domingo Martínez and Juan Simón Gutiérrez, who both followed in their master's footsteps and furthered this particular style. Valdés Leal was the only one to suggest yet another alternative model.

Keywords: Good Shepherd; Baroque iconography; Murillo; Valdés Leal; Sevillian painting.

Entre 1661 y 1665, Murillo ${ }^{1}$ realizó la primera versión moderna del Buen pastor niño conocida hasta el momento. Se trata de una de las pinturas que decoraban el altar

${ }^{1}$ Para profundizar sobre este artista, ver ANGULO ÍÑIGUEZ, Diego: Murillo. 3 vols. Madrid, 1981; VALDIVIESO GONZÁLEZ, Enrique: Murillo, catálogo razonado de 
efímero que se levantó frente a la iglesia de Santa María la Blanca para celebrar la concesión papal de la bulla Sollicitudo a favor de la concepción sin pecado original de la Virgen. Tenía por pareja un San Juanito con el cordero y, al centro, se situaba una Inmaculada 2 . Torre Farfán, en su crónica del evento, describe la pintura en los siguientes términos:

"A la mano derecha se fabricó otro Nicho, a proporción menor en longitud y latitud que el referido [el de la Inmaculada, que medía veinte pies de alto y catorce de ancho]; empero no en descuidos de los adornos. Formóse entre otras quatro Colunas de la misma corpulencia, y igual adorno que las otras. En él sobresalía vna bellíssima pintura del grande referido Artífice [Murillo]: es un tierno hermoso Niño, cuyo Cayado, y Pieles lo dan a conocer por Pastor amante de un rebaño de Corderos, que le cercan la piedad y le adoran las Sandalias. Aviendo dicho el Maestro no necessita la pintura de mis colores"3.

Igualmente, le dedica unos versos en su "descripción panegírica" final:

"Tierno Pastor en el uno,/ El que Monarca supremo/ Almas forma pasce amante,/ Fiel rebaño de Corderos./ La piel de hechura viste/ El Hazedor; y el intento/ Fue comprar la dicha agena/ Al afán del propio precio".

Con esta imagen, Murillo enlazó con los orígenes de una de las iconografías más antiguas de Jesús, puesto que se conservan ejemplos desde el siglo III. Precisamente en estas primeras representaciones Cristo aparece como un muchacho e incluso como un niño ${ }^{5}$. Así lo demuestran la versión escultórica de la Casa Pilatos ${ }^{6}$, las dos del Museo de Almería, algunas de las conservadas en el Museo de Estambul o la del Museo Pío Clementino vaticano, por citar algunos notables ejemplos.

pinturas. Madrid, 2010; VALDIVIESO GONZÁLEZ, Enrique: Murillo: sombras de la tierra, luces del cielo. Madrid, 1990; BROOKE, Xanthe y CHERRY, Peter: Murillo: scenes of childhood. Londres, 2011; y MENA MARQUÉS, Manuela: Bartolomé Esteban Murillo (1617-1682). Dibujos: catálogo razonado. Santander, 2015.

2 Actualmente, el Buen Pastor se encuentra en la colección de los descendientes de Mrs. George Lane, en Peterborough; el San Juanito con el cordero, en la National Gallery de Londres; y la Inmaculada, en el Museo del Prado. Los dos primeros cuadros han sido siempre adquiridos en pareja, salvo en su última venta, en 1840, cuando el Buen Pastor fue comprado por Rothschild y el San Juanito por Ashburton, quien a su vez lo cedió a la National Gallery. VALDIVIESO GONZÁLEZ, E.: Murillo, catálogo razonado de pinturas, op. cit., figs. 169 y 170.

${ }^{3}$ DE LA TORRE FARFÁN, Fernando: Fiesta que celebró la Iglesia Parrochial de $S$. María la Blanca, capilla de la Sta. Iglesia Metropolitana y Patriarchal de Sevilla en obsequio del nuevo breve concedido por N. Simo. Padre Alejandro VII, en favor del Puríssimo Mysterio de la Concepción sin Culpa Original de María. Sevilla, 1666, p. 8.

${ }^{4}$ Ibidem, p. 178.

5 GARCÍA BELLIDO, Antonio: Arte Romano. Madrid, 1972, pp. 662 y 772.

${ }^{6}$ Datado hacia 325 d.C., la propia Fundación Casa Ducal de Medinaceli pone en duda si representa a Jesús o a Hermes. En http://www.fundacionmedinaceli.org/coleccion/ fichaobra.aspx?id=578 (Consultado el 2-2-2017). 
La base documental que fundamenta esta iconografía se encuentra en las propias palabras de Jesús, pues según San Juan, declaró "yo soy el buen pastor"7, así como en una de las parábolas que narran San Lucas y San Mateo ${ }^{8}$, la cual enlaza, a su vez, con profecías del Antiguo Testamento. Concretamente, las referencias que equiparan al Mesías con el pastor de un rebaño se localizan en los libros de Isaías y Ezequiel y en el salmo $23^{9}$.

Para plasmar a Cristo como pastor, los artistas paleocristianos se basaron en tres modelos consagrados desde la Grecia arcaica y los adaptaron a las nuevas necesidades. Por un lado, tomaron al Moscóforo y a Hermes Crióforo, y por otro, a Orfeo. La asociación de estos dos dioses con Cristo no era tan solo formal, sino que también existían paralelismos más profundos que la reforzaban. A este respecto, hay que tener presente que tanto Hermes como Orfeo eran divinidades con cultos mistéricos, vinculadas con el más allá y ambos habían retornado del mundo de los muertos, por lo que, de forma natural, se puso en relación con la Resurrección. Así lo atestigua una de las pinturas de la catacumba de los santos Marcelino y Pedro, en Roma, donde en un arcosolio se ha representado a Orfeo como símbolo de la vida más allá de la muerte en vez de haber utilizado la figura de Cristo resucitado.

En el plano representacional, durante los primeros siglos no fueron necesarias las modificaciones. Tanto el Hermes Crióforo como el Moscóforo se plasman como un muchacho que viste un chitón corto o un exomis que le deja libre el hombro derecho y que lleva sobre sus hombros o en sus brazos un cordero y un ternero, respectivamente. Uno de los ejemplos más conocidos es el Hermes del Museo Barracco de Roma, considerado una copia romana de la célebre escultura efectuada por Calamis para su santuario de la ciudad beocia de Tanagra. Cuando este modelo pasó a representar a Cristo, no fue necesario alterar ningún elemento para la adaptación, salvo la utilización del ternero, que no fue empleada durante el cristianismo. Es precisamente por estas similitudes que en algunas obras de arte realizadas en los momentos en los que convivían las dos religiones, no siempre se puede precisar si se trata de un Hermes Crióforo o de un Buen Pastor.

Por su parte, la iconografía de Orfeo rodeado de animales salvajes, mansos gracias a la música de su lira, lo muestra como un joven ataviado con una túnica larga, un chitón o desnudo, con la sempiterna presencia del gorro frigio y la clámide. La escena tiende a enclavarse en un paisaje bucólico, representado de manera esquemática por algunos elementos vegetales, donde el dios aparece sentado sobre una piedra o de pie, apoyando un pie sobre ella. Esta composición era habitual en los sarcófagos, aunque también en los mosaicos de los triclinios y en escultura exenta, que en algunas ocasiones presentan además un fondo vegetal calado

7 Jn 10, 11-18.

${ }^{8}$ Lc 15, 4-7; Mt 18, 12-14.

9 Is 16, 1; Is 40, 11: "Como un pastor apacienta a su rebaño, en brazo recoge a los corderos, en su seno los lleva"; y Ez 34. 
plagado de animales. Algunos ejemplos de estos mosaicos los podemos encontrar en el Szépmúvészeti Múzeum de Budapest, en el Museo Archeologico Nazionale Antiquarium Turritano de Porto Torres, en Cerdeña, y en el Museo de Zaragoza; y de las esculturas, en el Museo Archeologico de Ravena, en el Museo Centrale di Montemartini de Roma, en el Museo Bizantino y Cristiano de Atenas (Figura 2) y en el Museo de Sabratha (Libia). La adaptación de Orfeo a Cristo fue superficial, ya que consistió simplemente en eliminar la lira y sustituir las bestias salvajes por un rebaño de ovejas.

Al igual que ocurría con los dos dioses clásicos, las primeras imágenes del Buen Pastor aparecieron vinculadas con la muerte, tanto en pinturas como en sarcófagos. Para el primer caso, resaltan las realizadas en el arcosolio del baptisterio de Dura Europos, de hacia el año 235, y las de las catacumbas de San Calixto, de Santa Priscila y de los santos Marcelino y Pedro; mientras que en el segundo, los numerosos ejemplos del Camposanto de Pisa y del Museo Pío Cristiano de los Museos Vaticanos, así como el sarcófago del siglo V conservado en la iglesia de Santa Cruz de Écija, son buenos testimonios. Su representación escultórica exenta se dio de forma paralela, como demuestran las versiones del Museo Pío Cristiano, del Museo Arqueológico de Estambul y de la Casa Pilatos de Sevilla, aunque al tratarse de obras descontextualizadas es complicado aseverar que sean cristianas en vez de paganas. Sea como fuere, la escultura sevillana está datada hacia el año 325 y formó parte de la colección que el I duque de Alcalá constituyó durante su virreinato en Nápoles (1558-1571). El Buen Pastor también fue muy común en la joyería, siendo un modelo usual en las piedras de los anillos desde los siglos III-IV; el British Museum conserva varios ejemplos de interés ${ }^{10}$. Finalmente, el Buen Pastor tuvo su representación musivaria, resaltando el que preside el ábside de Gala Placidia, en Ravena, aunque al ser ya del siglo V presenta algunas modificaciones respecto a la iconografía de Orfeo, como es la sustitución del cayado por una gran cruz dorada y la aparición del nimbo.

Tras este primer periodo de convivencia, el Hermes Crióforo desapareció irremediablemente a favor del Buen Pastor y no se volvió a tratar ni en los momentos posteriores de florecimiento de la cultura clásica. Mejor suerte tuvo Orfeo, quien tras el olvido de las centurias medievales, resurgió en el siglo XV con una lectura alegórica que lo hizo protagonista de obras plásticas, muchas de ellas incluso en contexto religioso, como es el caso de la intarsia de la capilla de Santa Catalina, en la basílica de Santo Domingo de Siena, así como de composiciones musicales, entre las que destaca la primera ópera, L'Orfeo de Monteverdi.

${ }^{10}$ Por citar algunos de ellos, ver inv. $\mathrm{n}^{\mathrm{o}} 1856,0425.17, \mathrm{n}^{\mathrm{o}} 1856,0425.21, \mathrm{n}^{\circ} 1865,0224.1$ y $\mathrm{n}^{\circ} 1856,0425.10$, este último más complicado porque también introduce los pasajes de Jonás y Daniel. Éstas y todas las referencias de inventario de obras pertenecientes al British Museum se pueden consultar en http://www.britishmuseum.org/research/collection online/search.aspx (Consultado el 2-2-2017). 
La iconografía del Buen Pastor también fue relegada durante el periodo medieval e igualmente comenzó su ascenso desde el siglo XV. Una de estas primeras versiones, fechada entre 1450 y 1465 y realizada en Ulm, es una xilografía conservada en el Staatliche Graphische Sammlung de Munich que muestra aún una conjunción de modelos infantiles que aún estaban fijándose, pues Cristo aparece como un Niño Jesús triunfante desnudo, con un orbe y un báculo cruciforme rematado por una banderola, a cuya presencia acude un cordero. Sin embargo, en la práctica totalidad de las representaciones del Buen Pastor tras su reaparición moderna lo muestra como adulto, alejándose así de los modelos paleocristianos en los que se lo plasma mucho más joven.

Por otra parte, la parábola del Buen Pastor no tenía un modelo representacional definitivo en el siglo XVI, sino que se optó por dos versiones, según si Jesús aparecía en primer plano contando el pasaje a los apóstoles, o a los escribas y fariseos si se sigue la versión de San Lucas, con una representación de la escena del pastor con el rebaño al fondo, o si era el propio Jesús el que portaba el cordero. Para el primer caso, hay tres grabados en el British Museum, dos realizados en Basilea en 1509 y en 1511, respectivamente, y otro en Colonia en $1580^{11}$. El segundo modelo es el que plasmó Frei Carlos hacia 1520 y que se conserva en el Museo de Arte Antiga de Lisboa; en este caso, porta el animal en los brazos. Rodeado por un paisaje podemos verlo en la bóveda del Gros-Horloge de Rouen, datado entre 1527 y 1529 , y con el animal sobre los hombros, aparece en la portada de Von den Conciliis und Kirchen, libro de Lutero publicado en Wittemberg en 1539 como respuesta a las predicaciones de Johannes Agricola ${ }^{12}$, y que hay que poner en relación directa con el Buen Pastor atribuido a Lucas Cranach del Angermuseum de Erfurt, datado hacia 1540 (Figura 3), puesto que los dos modelos son prácticamente idénticos. Estas versiones donde Jesús es el pastor será la tipología que triunfe, desbancando pronto a la otra en la que solo aparece como narrador.

En el panorama sevillano surge un nuevo modelo que parece retomar los orígenes mismos de este trasunto iconográfico, en el que el Buen Pastor vuelve a aparecer como un niño. Sin embargo, no se puede argumentar que haya una relación entre las esculturas de los comienzos del cristianismo y las pinturas barrocas sevillanas, puesto que el único ejemplo paleocristiano que había en la ciudad era Buen Pastor de la Casa Pilatos y no hay ningún dato que apunte a que fuera tomado como referencia. De hecho, en las pinturas del Buen Pastor niño éste nunca carga sobre sus hombros con el animal, como ocurre en la escultura. La trasposición de este tema desde un enfoque infantil hay que situarlo dentro de la tendencia postridentina de mostrar a la Santa Infancia que caló con tanta fuerza en la ciudad. Siguiendo esta idea, podemos comprobar que la iconografía del Buen

\footnotetext{
${ }^{11}$ Inv. $n^{\circ} 1860,0114.366$.

${ }_{12}$ En el British Museum de Londres hay un ejemplar, inv. nº 1895,1031.1026.
} 
Pastor niño es coetánea a otras en las que Cristo aparece también en sus primeros años, en estos casos con un enfoque simbólico que lo desliga de su cronología vital, como son el Niño Jesús triunfante ${ }^{13}$ y el Niño Jesús Pasional.

Parece que Murillo, en el retablo efímero de Santa María la Blanca, fue el primero en el arte moderno que representó al Buen Pastor como un niño, además de otorgarle una pareja que se convertiría en habitual, San Juanito con el cordero, pues así se completaba el ciclo del cordero relacionado con Cristo, que lo convertía tanto en pastor como en el propio animal. De esta manera, en el primero de los casos Jesús es el guía de las almas cristianas, representadas como un manso rebaño, las protege y las recupera si se extravían; mientras que en el segundo es una metáfora del cordero pascual que es sacrificado para eliminar los pecados, papel que el propio Jesús afrontará en su adultez a través de su crucifixión.

Murillo creó una afortunada tipología infantil, pues aúna una sugestiva belleza con una potente carga simbólica, y la reinterpreta en las tres ocasiones en las que representa este tema, sin caer en copias ni repeticiones. No obstante, en todas ellas hay una serie de patrones básicos que se repiten. De esta manera, Jesús aparece con unos cinco o seis años, es un niño rubicundo y pálido, con una delicadeza que no sería la propia de un muchacho que vive a la intemperie entre animales y que enlaza con su naturaleza divina y su inquebrantable espiritualidad. Viste una túnica larga y rosada, de cuello amplio y con las mangas remangadas, la misma que Murillo suele colocarle cuando lo representa en la niñez media, una vez superada su primera etapa infantil. De hecho, podemos encontrarlo vestido de manera similar en las tres versiones de Las dos Trinidades, ubicadas en el Fondo Cultural Villar Mir (1665-1670), en la Fundación Cajasol (1670-1680) y en la National Gallery (1670-1680), en los tres San José con el Niño de Madrid (16551660), el del Museo de Bellas Artes de Sevilla (1665-1668), el del Hermitage (c. 1670) y el de Castletown (1675-1680) y en el San Félix Cantalicio con el Niño Jesús de Gosford House (1670-1680) ${ }^{14}$. Las únicas ocasiones en la que el Niño aparece vestido con una túnica de otro color, plateado, blanco y azul respectivamente, es en Las dos Trinidades de Estocolmo (c. 1640), las dos pinturas del Abrazo del Niño Jesús y San Juanito (1660-1670) y la Sagrada Familia con San Juanito de Budapest y su versión valenciana ${ }^{15}$.

13 A este respecto, ver PÉREZ LÓPEZ, Nerea V.: "Murillo y la iconografía del Niño Jesús dormido sobre la cruz", Boletín de Arte, 36, 2005, pp. 145-154.

${ }^{14}$ VALDIVIESO GONZÁLEZ, E.: Murillo, catálogo razonado de pinturas, op. cit., figs. 235, 282, 283, 102, 103, 104, 183, 272, 338 y 328, respectivamente.

15 VALDIVIESO GONZÁLEZ, E.: Murillo, catálogo razonado de pinturas, op. cit., figs. 5, 171, 172, 236 y 237. En algunas imágenes de la Virgen con el Niño y en la Sagrada Familia del pajarito lleva una camisola, pero en estas ocasiones Jesús está representado con menor edad. 
Otra de las novedades que aporta Murillo es que, a diferencia del Buen Pastor paleocristiano y del renacentista, le otorga una nueva vestimenta más acorde con su momento histórico, pues coloca sobre la túnica un pellizo de corte irregular, propio del mundo pastoril, que le cubre el pecho y el torso y que se ciñe a la cintura con un trozo de tela. A partir de estos momentos, el Buen Pastor portará constantemente esta indumentaria, que el artista completa con un delgado cayado de punta metálica y curva que sostiene en una de sus manos, mientras que apoya la otra en una de las ovejas de su grey, las que por otra parte, están plasmadas con gran realismo.

Son pinturas serenas y apacibles en las que se combina el paisaje bucólico y la sosegada belleza de las figuras, tanto humanas como animales, con una intensa carga devocional. Las escenas siempre están ambientadas en un exterior campestre, más claro y despejado que en las representaciones de San Juanito que conforman sus parejas. Este diferente uso de la luz en los dos personajes también tiene su carga simbólica. En el caso de Jesús, su naturaleza divina ya explicaría que le correspondiese la mayor intensidad lumínica, pero además en las Sagradas Escrituras hay referencias a su luz, como en la profecía de Isaías ${ }^{16}$ y en la del sacerdote Zacarías, quien dice que Dios vendrá "para alumbrar a los que yacen en las tinieblas y en la sombra de la muerte" 17 , es más, el propio Jesús se define a sí mismo como "yo soy la luz del mundo" 18 . El Bautista y su relación lumínica con Jesús tiene su más claro referente en el evangelio de San Juan, donde en su primer capítulo se define el papel de ambos: "Hubo un hombre enviado por Dios, que se llamaba Juan. Éste vino como testigo, para dar testimonio de la luz, a fin de que por medio de él todos creyesen. No era él la luz, sino enviado para dar testimonio de la luz. El Verbo era la luz verdadera, que ilumina a todo hombre que viene a este mundo" $"$. Así, con esta diferencia en la claridad se establece la jerarquía entre los dos personajes y se recuerda que San Juan, el último profeta y enlace entre ambos testamentos, pertenece todavía al mundo previo a la llegada del Mesías, que trae la luz.

La primera versión del Buen Pastor de Murillo que ya hemos comentado gozó de mucho éxito, tanto en el ámbito sevillano como fuera de las fronteras nacionales, pues en 1750 se encontraba en París y, tras varios cambios de propietario, llegó a Londres en $1801^{20}$. Cuenta, entre otras, con una buena copia de taller en el Museum of Fine Arts de Boston y otra más pequeña y esbozada en la Dulwich Picture Gallery de Londres, además del cuantioso número de copias
${ }^{16}$ Is 9,2 .
${ }^{17} \mathrm{Lc} 1,79$.
18 Jn 8, 12.
19 Jn 1, 6-9.
${ }^{20}$ VALDIVIESO GONZÁLEZ, E.: Murillo, catálogo razonado de pinturas, op. cit., p. 382 . 
que aparecen con cierta frecuencia en el mercado de $\operatorname{arte}^{21}$, a la vez que se considera como fuente de inspiración de la Cottage girl de Gainsborough, pintada en 1785 y conservada en la National Gallery of Ireland, en Dublín ${ }^{22}$. Todo ello denota el interés que suscitó fuera del ámbito español, contribuyendo a que se asentara tanto este modelo como el estilo murillesco en otras escuelas europeas. La escena se sitúa en un paisaje agreste con arboleda a contraluz y un río a la derecha. Al centro aparece el niño de pie, calzando unas sandalias de tiras a diferencia de las otras dos versiones, en las que va descalzo. Jesús deja caer su peso en la pierna izquierda y flexiona la derecha, creando así un suave ritmo curvo y ascendente que conduce a su mirada, y de ésta a la luz dorada que se abre en la parte superior del lienzo y que él observa extasiado en señal de agradecimiento por haber podido recuperar la oveja perdida que está acariciando.

La segunda versión de Murillo fue realizada entre 1665 y 1670 (Figura 3). En 1744, la reina Isabel de Farnesio la adquirió a los herederos del cardenal Molina y pasó a La Granja de San Ildefonso, y de allí al Museo del Prado, su ubicación actual. En esta ocasión, Jesús aparece sentado delante de una columna rota sobre un alto podio y unos fragmentos de entablamento, dándole un aspecto aún más bucólico a la escena. Murillo utiliza el recurso de las ruinas en otras pinturas protagonizadas por niños, pero sin ser elementos arquitectónicos clásicos. Igualmente, la columna sobre podio se repite como fondo de forma habitual, aunque éste es, además del contemporáneo San José con el Niño del Museo de Bellas Artes de Sevilla, el único caso en el que el fuste es acanalado. Junto a Jesús se encuentra una de las ovejas, mientras el resto del rebaño pasta al fondo. Es la única de las tres pinturas en la que el niño, en vez de clavar la vista en el cielo, mira al espectador, con una expresión seria y serena que muestra su profundidad interior. Ceán Bermúdez señaló las semejanzas en la posición del Niño con la estampa del frontispicio de una serie de grabados mitológicos de Stefano della Bella, realizados en 1644. En esta imagen aparece un joven Cupido sentado entre ruinas clásicas y con una pierna en alto, con los dioses del Olimpo tras él. Como apunta Valdivieso en su monografía sobre Murillo, la estampa pudo servir como un modelo de inspiración inicial para la postura, pero sin duda el artista no la emplea tal cual sino que la interiorizó, puesto que el Buen Pastor que plasmó sigue su canon infantil habitual ${ }^{23}$.

${ }^{21}$ En este sentido, destaca la pintura subastada por Sotheby's New York, 1-2-2013/22-2013, lote 508 .

22 VALDIVIESO GONZÁLEZ, E.: Murillo, catálogo razonado de pinturas, op. cit., pp. 167-168.

${ }^{23}$ CEÁN BERMÚDEZ, Juan Agustín: Colección litográfica de los cuadros del rey de España. Vol. I, lám. 32; y VALDIVIESO GONZÁLEZ, E.: Murillo, catálogo razonado de pinturas, op. cit., p. 168. 
En el Museo del Prado y en el gabinete de artes gráficas del Museo del Louvre (Figura 4) se conservan sendos dibujos autógrafos de Murillo que representan, de una manera muy similar, al Buen Pastor $^{24}$, y ambos parecen contemporáneos al lienzo. El primero de ellos está más esbozado, mostrando algunas dudas en cuanto a la colocación del rostro y del brazo izquierdo que en el parisino están resueltas, siendo un diseño ya terminado que incluye los puntos de luz y sombra. Ambos parten de la pintura del Prado y la reinterpretan, creando una obra completamente diferente aunque con un recuerdo a la madrileña, especialmente en la postura de la cabeza, el torso y las piernas del Niño. Las diferencias se localizan en la colocación del cayado que, en vez de acompañar la línea oblicua marcada por la pierna, está erecto, apoyado en el suelo y sujetado por la mano. También se ha incluido un sombrero sobre la cabeza de Jesús y el cordero ha cambiado de posición. En la versión del Prado se ha perfilado con grafito otro cordero bajo el bastón, mientras que en la parisina se aprecia, esbozada, una segunda oveja a la izquierda de la imagen y el resto del rebaño pastando a la derecha, en un plano intermedio.

La tercera y última pintura, de pequeñas proporciones, está datada entre 1675 y 1682 y está actualmente en el Städelsches Kunstinstitut de Frankfurt am Main (Figura 5). En ella, Jesús aparece de pie en primer plano, ocupando gran parte del lienzo y vestido como en las otras representaciones murillescas del Buen Pastor, aunque en esta ocasión su túnica tiene matices malvas. Alza su mirada a los resplandores áureos que iluminan la parte superior del cielo y que parecen dirigirse hacia su rostro, el cual muestra su intensa espiritualidad. Es una obra de madurez, y en ella Murillo emplea una pincelada más suelta que en los lienzos anteriores, si bien apenas modifica el modelo infantil que había creado hacía más de veinte años.

Finalmente, en el Paul Getty Museum se encuentra un dibujo del Buen Pastor efectuado por Murillo y fechado hacia $1670^{25}$ (Figura 6). Muestra una composición que no se aprecia en ningún lienzo del artista, tan solo presenta algún paralelismo en la posición del brazo derecho y de la cabeza con el San Juanito con el cordero de la National Gallery de Londres (c. 1660-1665), aunque éstos son los únicos puntos en común, por lo que son lo suficientemente distintos como para considerar la versión de Malibú como una reinterpretación del cuadro británico. En el dibujo se observa a Jesús de pie, con una pierna apoyada en una suave elevación del terreno, cargando el cordero sobre su hombro izquierdo y creando con el cayado una marcada diagonal. Es ésta la única versión de Murillo en el que un niño, ya sea Jesús o el Bautista, porta el animal; a pesar de lo esbozado del dibujo, se aprecia cómo el elevado peso recae sobre su espalda, alegoría de la abrumadora

\footnotetext{
${ }^{24}$ Inv. ${ }^{\circ} \mathrm{D} 06319$ y n ${ }^{\circ} 18439.2$, respectivamente.

${ }^{25} \mathrm{http}: / / \mathrm{www}$.getty.edu/art/collection/objects/454/bartolome-esteban-murillo-thechrist-child-as-the-good-shepherd-spanish-about-1675-1680/ (Consultado el 2-2-2017).
} 
carga que debe soportar Cristo, consciente también desde una perspectiva física de la ardua tarea que se le ha encomendado. Quizás por ello el pintor le otorgó una mirada directa al espectador inusitadamente seria, muy diferente de la amable sonrisa del San Juanito de Londres.

El modelo del Buen Pastor niño creado por Murillo alcanzó un considerable éxito desde época muy temprana y se extendió a lo largo de las centurias siguientes, sobre todo debido a que se realizaron grabados de las pinturas, al traslado de dos de sus versiones fuera de las fronteras nacionales y a la apertura del Museo del Prado, hechos que favorecieron enormemente su difusión. Como resultado, se produjo una ingente cantidad de copias de distinto nivel de calidad, aunque ninguna comparable a los niveles técnicos del artista sevillano. Muchas de estas pinturas, de pequeño formato, se situaron en la puerta de los sagrarios de los retablos, compartiendo protagonismo con el Niño Jesús triunfante, sobre todo en el ámbito granadino ${ }^{26}$.

Un talentoso seguidor de Murillo, contemporáneo al maestro, realizó un Buen Pastor que se encuentra en el Hunterian Museum \& Art Gallery, en la Universidad de Glasgow (Figura 7). Resulta especialmente interesante porque Jesús aparece entretenido mientras envuelve sobre sí misma una rama espinosa, fabricando de esta manera una corona de espinas. Con esta alusión, el artista ha plasmado en la pintura el doble significado que el cristianismo confiere a la figura del cordero en relación con Jesús, es decir, a la guía de almas se ha añadido el de la premonición del sacrificio para el perdón de los pecados. Hay que resaltar que la iconografía del Niño Jesús de la espina parece que tiene también un origen sevillano, puesto que se considera que el primero que la plasmó fue Zurbarán hacia 1644-164527, en sus tres pinturas de la Casa de Nazaret ${ }^{28}$ y en sus dos versiones simplificadas del Museo de Bellas Artes de Sevilla, en las que solo aparece Jesús. La diferencia con el Buen Pastor que comentamos radica en la ausencia de la gota de sangre en el dedo, que ocasiona una profunda y melancólica reflexión acerca de su desenlace final en las obras del extremeño.

Esta relación del Buen Pastor con la Pasión, aunque muy poco frecuente, no es completamente novedosa, puesto que Hieronymous Wierix representó un Buen

${ }^{26}$ Algunos ejemplos de esta ubicación lo encontramos en el inventario de patrimonio mueble del Instituto Andaluz de Patrimonio Histórico, inv. $\mathrm{n}^{\circ} 79879, \mathrm{n}^{\circ} 81421, \mathrm{n}^{\circ} 77815$ y $\mathrm{n}^{\circ} 79010$, http://www.iaph.es/patrimonio-mueble-andalucia/frmSimpleArt.do (Consultados el 2-2-2017). En los dos primeros se aprecia la inspiración murillesca, mientras que los dos últimos, al ser más tardíos, incorporan elementos que recuerdan a la iconografía de la Divina Pastora.

${ }^{27}$ DELENDA, Odile: Francisco de Zurbarán, catálogo razonado y crítico. T. I. Madrid, 2010, p. 595. Ver también GÓMEZ PIÑOL, Emilio: "Una obra inédita de Zurbarán: 'El niño de la espina' de Oñate", Archivo Español de Arte, XXXIX, 1966, pp. 9-24.

${ }^{28}$ Se encuentran en el The Cleveland Museum of Art, en el Fondo Cultural Villar Mir y en la colección Colomer de Madrid, proveniente ésta última del convento de las Salesas Reales de Madrid y muy dañada durante la Guerra Civil. 
Pastor adulto con una voluminosa corona de espinas y las llagas del martirio ${ }^{29}$. Lleva el torso al descubierto y las piernas y la espalda cubiertas por la túnica. En segundo plano vuelve a aparecer, vestido de pastor y acompañando a su rebaño, y al fondo, sobre una colina, se aprecian las tres cruces del Gólgota. El Museo del Louvre guarda otro grabado de factura más modesta, considerado de escuela italiana del siglo XVI, en el que aparece Cristo adulto, vestido tan solo con el sudario, cargando sobre sus hombros el cordero y la cruz y arrodillándose para recoger un cáliz ${ }^{30}$. La relación entre la pintura sevillana y estos grabados tan solo existe en el hecho de haber compartido la idea de unir estas dos iconografías cristológicas en una misma imagen, elevando así su carga simbólica.

Juan de Valdés Leal, basándose en las características que ya se habían asentado con Murillo y sus seguidores y haciéndolas propias, propuso un modelo diferente de Buen Pastor (Figura 8) en una pintura que fue dada a conocer en 1916 por Gestoso, quien emitió un juicio no muy favorable hacia ella: "No estuvo muy afortunado Valdés Leal [...] La figura, de tamaño académico, es exageradamente abultada y aunque la dulce expresión de su rostro hace simpático ese abultamiento, perjudica al efecto estético de la imagen" ${ }^{1}$. Si bien Valdés Leal no alcanzó el grado de idealización estética de Murillo, debió obtener una notable popularidad, puesto que han llegado hasta el presente varias imitaciones, siendo una de las mejores la pintura localizada en Haddo House, en Aberdeenshire, donde está erróneamente catalogada como del círculo de Murillo. El original, sin embargo, que Gestoso conoció en la colección de don Luis Gamero Cívico en Sevilla, ha estado en paradero desconocido hasta que en 2006 el profesor Valdivieso la localizó en una colección particular madrileña ${ }^{32}$.

El lienzo original se fecha hacia 1680, en el periodo de madurez del artista, como queda patente en la soltura de la pincelada y en la maestría de su ejecución, gracias a la cual Valdés Leal crea una escena de aparente sencillez pero con una potente carga devocional, mostrando el profundo sentimiento de fe de Jesús desde su más tierna edad. Está representado como un niño de bucles rubios y tez pálida, con ojos redondeados, labios carnosos y mejillas encarnadas,

${ }^{29}$ Biblioteca Nacional de España, signatura Col. Albert/1121/253, http://catalogo. bne.es/uhtbin/cgisirsi/?ps=EOfW1Cd7AQ/BNMADRID/246110238/123 (Consultado el 2-2-2017).

${ }^{30}$ Musée du Louvre, inv. $\mathrm{n}^{\circ} 4017$ LR, http://arts-graphiques.louvre.fr/detail/ oeuvres/1/519114-Le-bon-pasteur-portant-sa-croix (Consultado el 2-2-2017).

31 GESTOSO Y PÉREZ, José: Biografía del pintor sevillano Juan de Valdés Leal. Sevilla, 2008, pp. 195-196, lám. 29.

32 VALDIVIESO GONZÁLEZ, Enrique: "Valdés Leal, pintor de la Santa Infancia. A propósito de un Buen Pastor inédito", Boletín del Seminario de Estudios de Arte y Arqueología, LXXV, 2009, pp. 197-202; y VALDIVIESO GONZÁLEZ, Enrique: Juan de Valdés Leal. El sacrificio de Isaac. Madrid, 2014, pp. 95-97, fig. 58. 
constituyendo un ideal de belleza diferente al establecido por Murillo pero igualmente válido. Aparece ataviado con una túnica larga de tonalidades que se mueven entre el rosa y el malva, con las mangas remangadas y el pellizo protegiendo su torso; a esta indumentaria Valdés Leal ha incorporado un manto azul oscuro. El Niño se nos muestra en primer plano, con el rostro suavemente inclinado y la mirada puesta en el cielo, está sentado entre riscos que se elevan a la derecha de la composición, con la pierna izquierda en escorzo. Con una mano izquierda sujeta suavemente el cayado mientras coloca la derecha sobre el pecho, con los dedos corazón y anular unidos, repitiendo un gesto devocional típico del periodo barroco.

En las copias anónimas conservadas hay un foco de luz que surge del centro de la parte superior del lienzo y cae sobre su figura, aseverando el esquema triangular de la composición. El Niño es de menor edad que en las versiones de Murillo y por ello muestra ciertos aspectos anatómicos propios de la primera niñez, como son la redondez del mentón, de las muñecas y de los tobillos, así como las manos carnosas y con hoyuelos. Se ha omitido la oveja en primer plano, que está sempiternamente presente en las demás versiones del Buen Pastor. Su alusión, muy sutil, aparece al fondo a la izquierda, donde se abre un paisaje apenas esbozado en el que se aprecia el rebaño, custodiado por dos ángeles.

Como es frecuente en esta iconografía, esta imagen tenía por compañera un San Juanito con el cordero, como atestigua la pareja de lienzos conservados en las dependencias parroquiales de la prioral de Santa María, en El Puerto de Santa María (Cádiz). En efecto, junto a la copia del siglo XVIII del cuadro del Buen Pastor que comentamos, se encuentra otra pintura de formato similar que muestra al Precursor en el desierto acompañado por un cordero, lo que nos hace suponer que se trata igualmente de una copia de una pintura de Valdés Leal que no se ha conservado o de la que, al menos, no se conoce su paradero.

Domingo Martínez no realizó ninguna pintura del Buen Pastor, o al menos no se tiene constancia de ello ni parece haber llegado a nuestros días ninguna atribución. Sin embargo, en la colección Brauer de Zurich, donde se conservan cuarenta y cuatro dibujos del artista, hay dos de ellos que Pérez Sánchez identificó como tanteos para el Buen Pastor o San Juanito ${ }^{33}$. Podemos apuntar que se trata de Jesús, puesto que su indumentaria se parece a la que Murillo estandarizó en esta iconografía y se aleja de la típica representación del Bautista. Las diferencias son aún más apreciables si se comparan con otro de los dibujos de Martínez en la misma colección, en el que aparece San Juanito con el cordero ${ }^{34}$. Las dos imágenes del Buen Pastor representan al mismo niño desde dos puntos de vista, uno aparece girado de tres cuartos y otro de perfil. En ambos, alza la mirada al cielo y se lleva una mano al pecho. La postura se acerca bastante a la pintura del Buen

${ }^{33}$ PÉREZ SÁNCHEZ, Alfonso E.: "Dibujos de Domingo Martínez", en Domingo Martínez, en la estela de Murillo. Sevilla, 2004, pp. 46-49, figs. 122 y 123.

${ }^{34}$ Ibidem, p. 47, fig. 2.9. 
Pastor de Valdés Leal, aunque la estética infantil recuerda más a Murillo, especialmente la del Niño de tres cuartos.

Para finalizar con las pinturas barrocas sevillanas del Buen Pastor, hay que citar la efectuada por Juan Simón Gutiérrez hacia 1700-1710 (Figura 9), que fue dada a conocer por Fernando Quiles ${ }^{35}$. En ella, el artista toma como modelos de referencia tanto el cuadro de Murillo del Museo del Prado como el dibujo del Louvre, que debía de conocer posiblemente mediante un grabado, puesto que invierte los elementos que toma como inspiración. Es en la postura del Niño donde se aprecian mejor esas referencias. El torso y las piernas son el punto de unión de las tres obras, puesto que están plasmados de manera similar y en la misma dirección; no obstante, el resto del cuerpo de Jesús, es decir, la cabeza y los brazos, así como el cordero, son una versión volteada del dibujo, al que sigue de cerca. El paisaje de Gutiérrez es más oscuro que en sus referencias murillescas, puesto que Jesús parece estar situado a la entrada de una cueva rocosa, tras él hay un río y de fondo muestra un paisaje en lejanía que es muy similar al que Murillo pintó en el San Juanito con el cordero del Kunsthistorisches Museum de Viena. En relación con el cuerpo, se comprueba cómo Gutiérrez no llega al dominio anatómico del maestro, sino que tiene algunas carencias en las proporciones. Así, el pie que deja ver su planta es demasiado pequeño y la cabeza y los ojos excesivamente grandes. Sin embargo, se trata de una pintura correcta que cumple sus cometidos estéticos y devocionales.

Por lo tanto, tras este recorrido podemos comprobar que, aunque las raíces de la iconografía del Buen Pastor niño se hunden en los primeros momentos del arte paleocristiano y se apoyan directamente en referentes clásicos, el modelo cae en el olvido durante las centurias medievales y no reaparece en su versión infantil hasta la segunda mitad del siglo XVII. Esta ruptura tan prolongada ocasionó que su renacimiento no suponga una mera continuación, sino que surge con un enfoque nuevo orientado al momento histórico en el que se encontraba inmerso, en el cual se potenciaba la presencia infantil de las figuras sagradas para conmover al fiel y favorecer la devoción. En este sentido, Sevilla tuvo un papel preponderante en la creación y en la consolidación de varias de estas iconografías, entre ellas la del Buen pastor niño que aquí nos ocupa. Murillo, en el altar provisional de Santa María la Blanca, fue el primero que se enfrentó a esta representación y el que sentó las bases que definirían el modelo en las décadas posteriores, siendo contestado solo por Valdés Leal.

Fecha de recepción: 26 de septiembre de 2016

Fecha de aceptación: 6 de abril de 2017

${ }^{35}$ QUILES GARCÍA, Fernando: "Apuntes sobre la obra y vida de Juan Simón Gutiérrez”, Atrio. Revista de Historia del Arte, 0, 1988, pp. 109. Pertenecía al marqués de Casa Argudín y fue subastada por Setdart el 4-6-2015. 


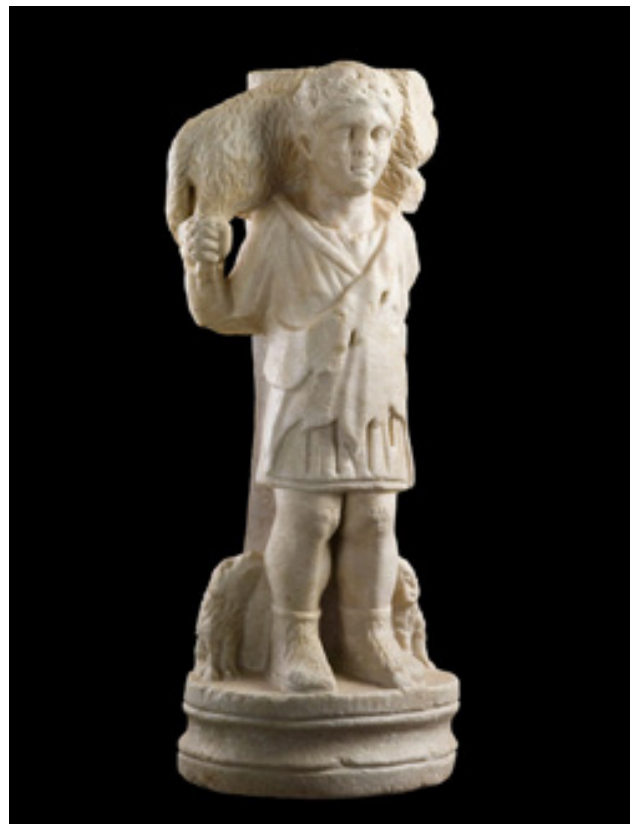

Figura 1. Anónimo, Buen Pastor, primera mitad del siglo IV, Museo Bizantino y Cristiano, Atenas.

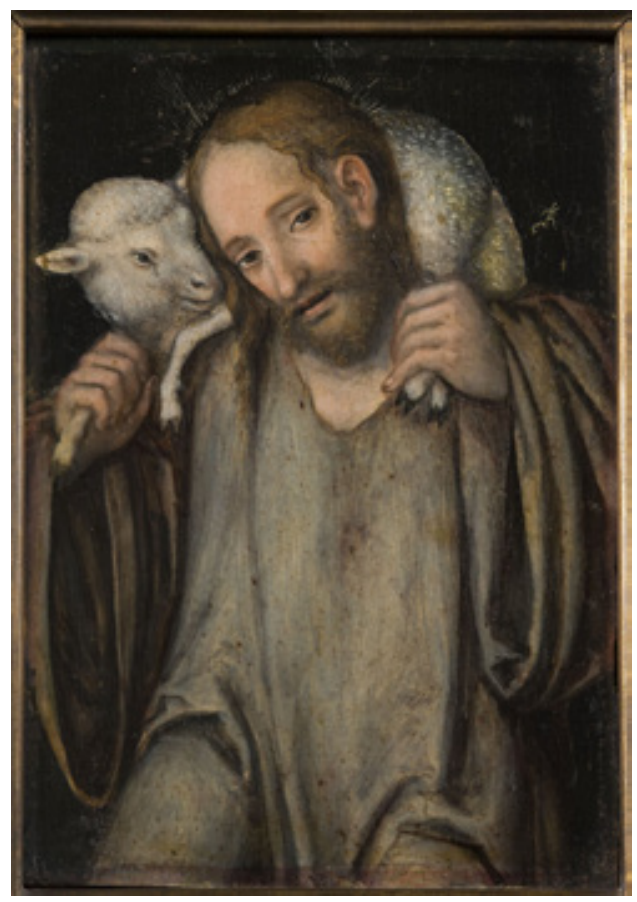

Figura 2. Lucas Cranach, Buen Pastor, hacia 1540, Angermuseum, Erfurt. 
Figura 3. Bartolomé Esteban Muri1lo, Buen pastor niño, 1665-1670, Museo del Prado, Madrid.

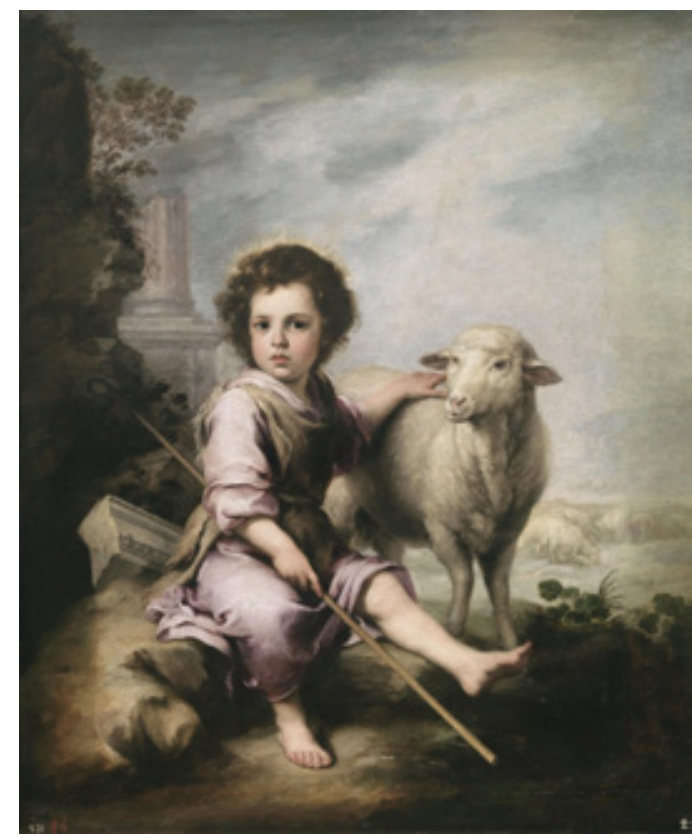

Figura 4. Bartolomé Esteban Murillo, Buen Pastor niño, hacia 1670, Musée du Louvre, París.

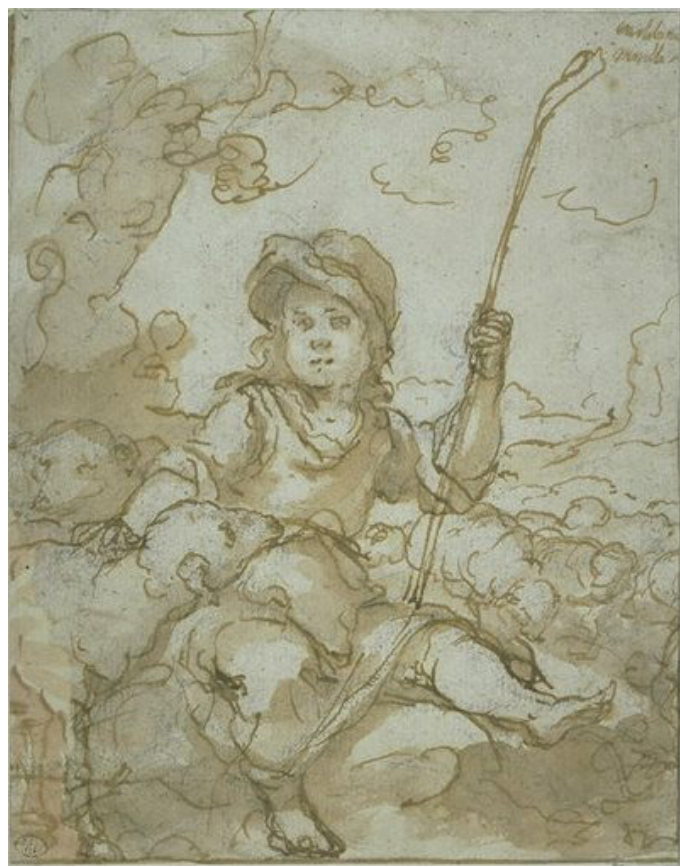

LABORATORIO DE ARTE 29 (2017), pp. 311-328, ISSN 1130-5762 e-ISSN 2253-8305 - DOI http://dx.doi.org/10.12795/LA.2017.i29.17 


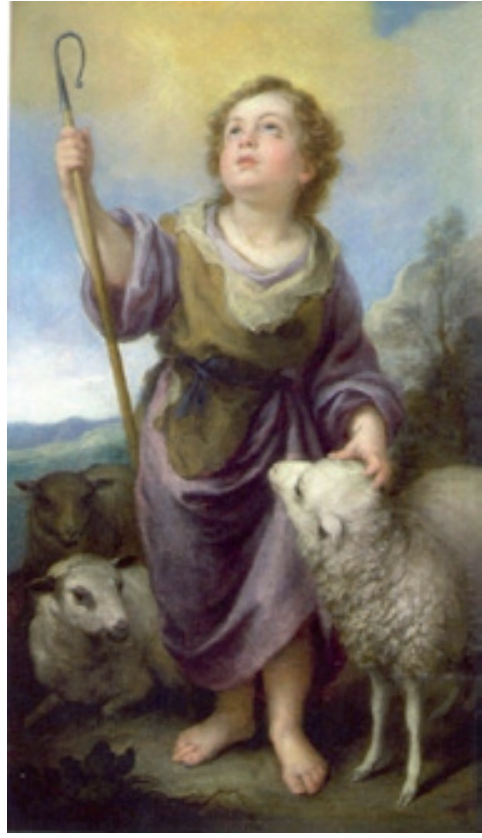

Figura 5. Bartolomé Esteban Murillo, Buen Pastor niño, 1675-1682, Städelsches Kunstinstitut, Frankfurt am Main.

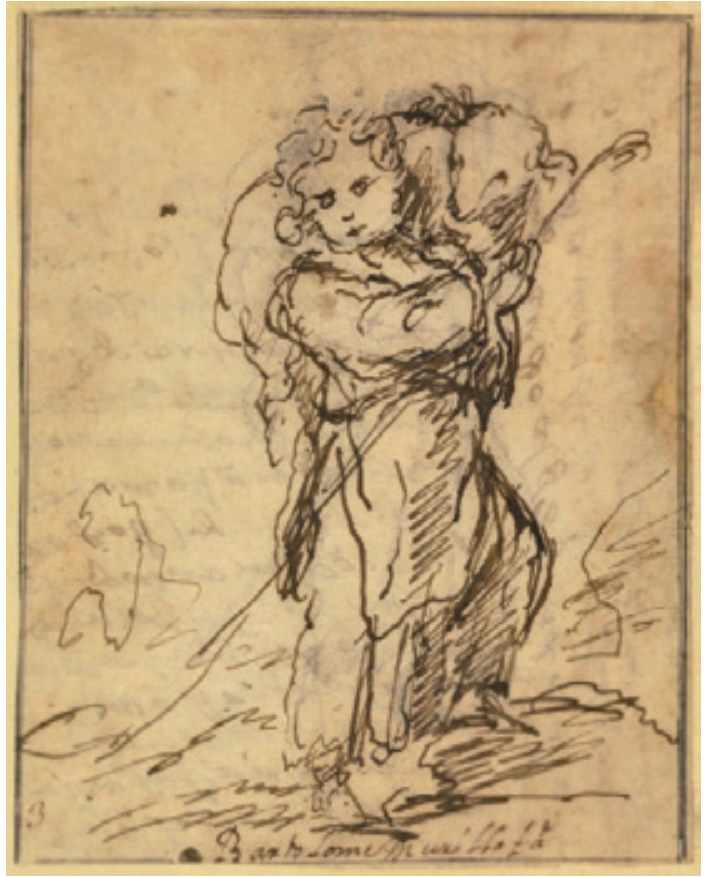

Figura 6. Bartolomé Esteban Murillo, Buen Pastor niño, 1675-1680, Paul Getty Museum, Malibú. 


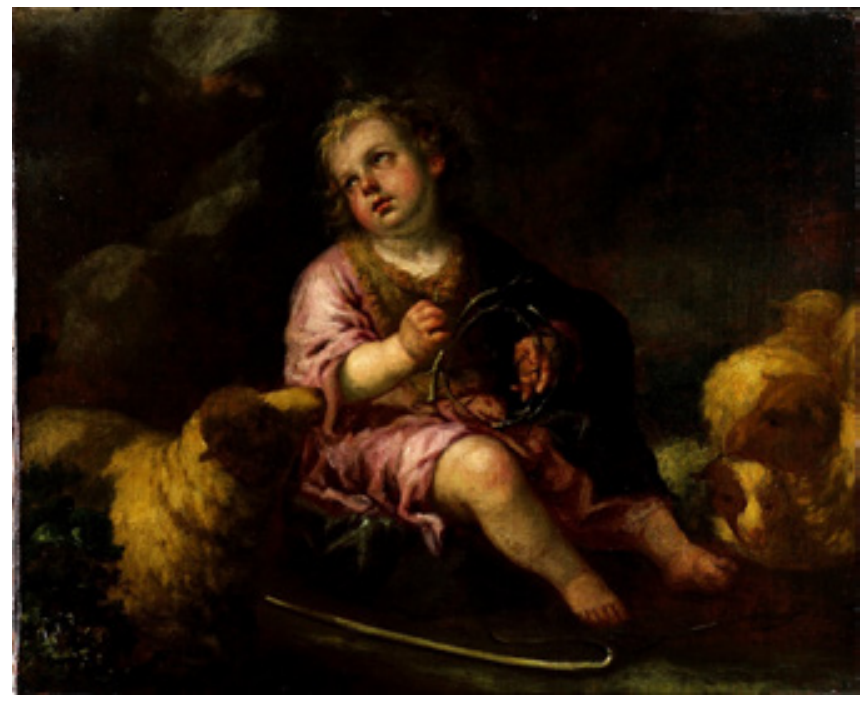

Figura 7. Seguidor de Murillo, Buen pastor niño, hacia1665, Hunterian Museum and Art Gallery William Hunter collections, Glasgow University.

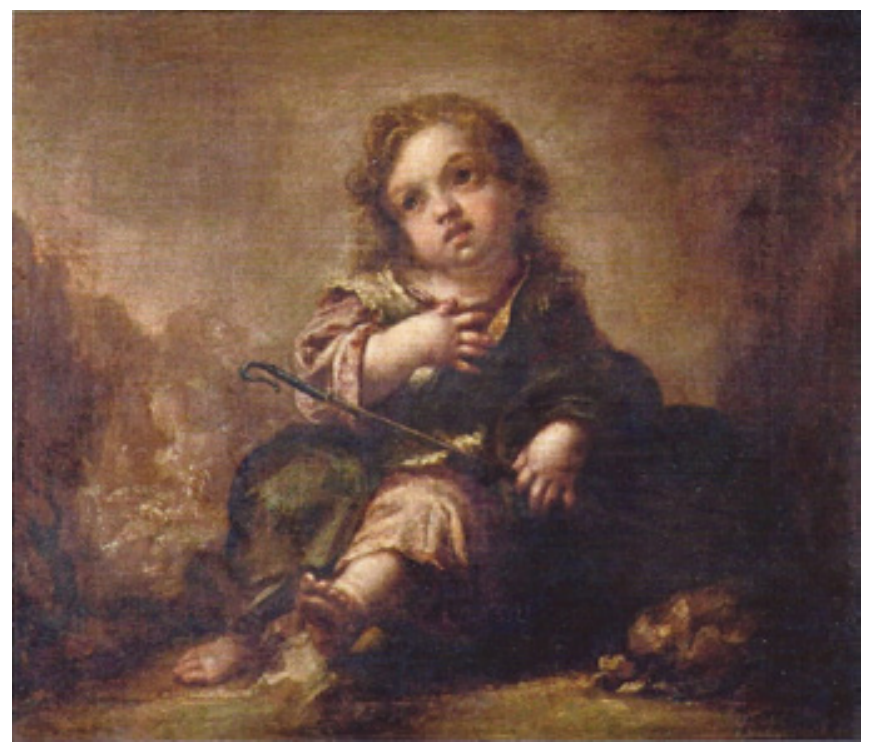

Figura 8. Juan de Valdés Leal, Buen Pastor niño, hacia 1680, colección particular, Madrid. 


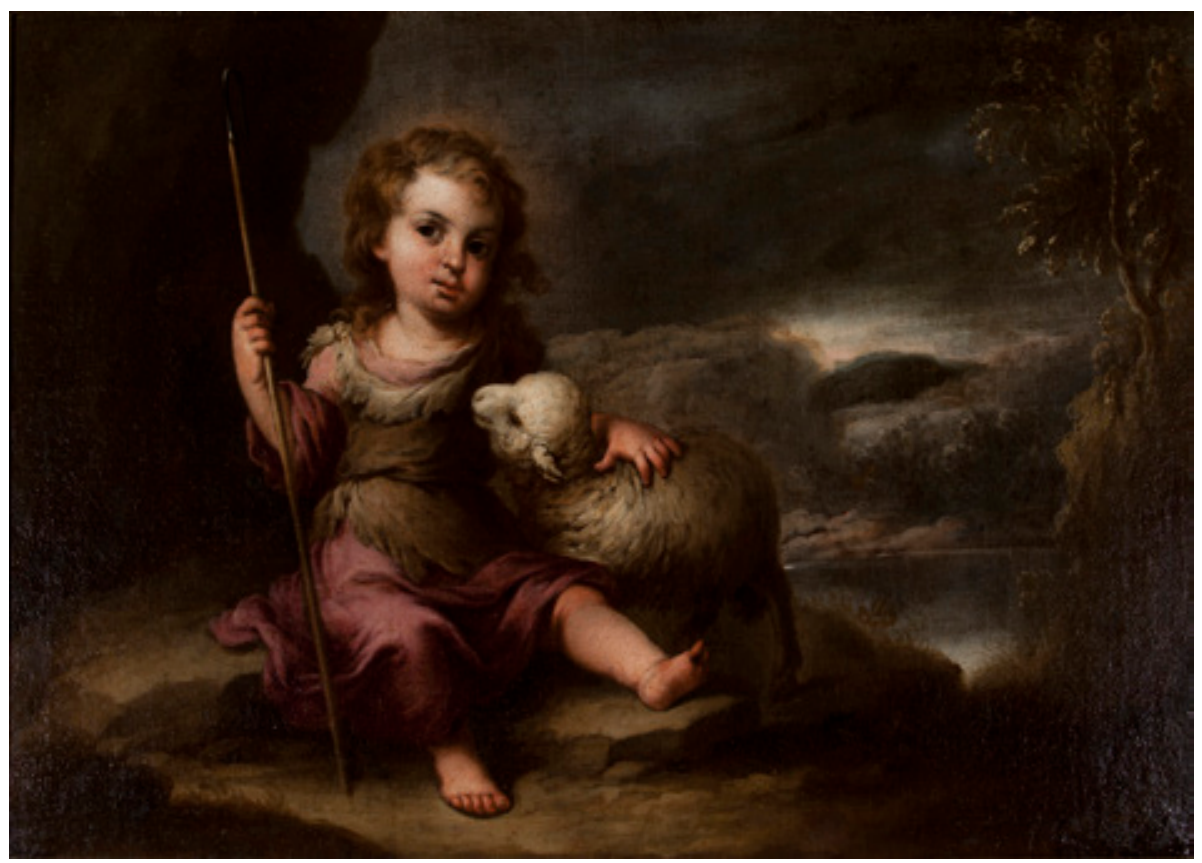

Figura 9. Juan Simón Gutiérrez, Buen Pastor niño, hacia 1700-1710, mercado de arte. 